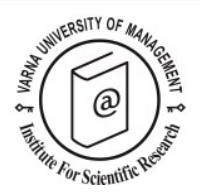

\title{
Tourist destination network analysis: The ego network role
}

\author{
Salvatore lannolino ${ }^{1}$ and Giovanni Ruggieri ${ }^{2 *}$
}

Received: 16/06/2015 Accepted: 31/03/2017

\footnotetext{
1 University of Palermo, Viale delle Scienze, Edificio 13, 90128 Palermo, Italy; tel: 00393472391431 ; e-mail: salvatore.iannolino@unipa.it

2 University of Palermo, Viale delle Scienze, Edificio 13, 90128 Palermo, Italy; tel: 0039 3472391431; e-mail: giovanni.ruggieri@unipa.it

* Corresponding author
}

\begin{abstract}
This paper aims to analyse the different roles that enterprises have within a tourist destination by identifying the presence and possible role of leaders within the system. The Social Network Analysis (SNA) is a tool that offers a greater degree of understanding of the operation of the destination. The map of commercial relations between the leading players of tourist supply can provide greater insight into the main relations existing between enterprises and the principles that ensure and regulate operation. In keeping with this objective and building on the results of a previous paper (lannolino and Ruggieri, 2012), the authors have focused their attention on the role of some enterprises operating in San Vito Lo Capo (Italy) to determine the extent of their aggregating force vis-à-vis the destination. The ego-network analysis (ENA) has been applied to the existing relations between the enterprises at the destination San Vito Lo Capo, to determine the presence or absence of groups of enterprises, called Egos, which, with respect to the others, play an important role or are to be considered key subjects for the entire system in commercial terms. Following on this first results, the paper explores ways in which enterprises belonging to the ego networks are the key players responsible for a better climate of cooperation and trust among all of the system's enterprises.
\end{abstract}

(C) 2017 Varna University of Management. All rights reserved

Keywords: tourism destination, social network analysis, ego-network, family cluster, sub-network influence.

Citation: lannolino, S., G. Ruggieri (2017) Tourist destination network analysis: The ego network role. European Journal of Tourism Research 17 pp. 231-245

Social Network Analysis: background

The production of goods and services within a tourist destination necessarily implies a set of collaborations between the various stakeholders (Czernek, 2013; Baggio, 2011; Beritelli, 2011). The presence or absence of these relationships, whether formalized or spontaneous and not formalized, represents the grid or network of a tourist destination (Baggio et al., 2010; Baggio \& Cooper, 2010; Graci, 2013).

A recent line of research in the literature on tourism has analysed destinations based on the assumption that they are a set of elements that are strongly interconnected (Merinero- 
Rodríguez \& Pulido-Fernández, 2016(a); Baggio, 2013; Fyall, Garrod \& Wang, 2012; Perry, 2012). This grid, or system, is referred to in the literature as mix (destination mix), that is a set, both indistinct and non-identifiable, whose presence is able to ensure the operation of the tourist destination as a whole, thus determining its success as well. This has resulted in the need to find tools and techniques that could be used to study the destination, focusing on the relationship between components and elements of a tourist destination.

The Social Network Analysis (SNA) has addressed this need (Latour, 2013; MerineroRodríguez \& Pulido-Fernández, 2016(b)), as its unit of analysis is the network as a whole. In order to achieve this goal, it uses techniques that analyse relationships between individuals, groups or organizations (Kilduff, \& Brass, 2010). The importance of considering relationships as an element constituting human nature was well expressed by Kilduff \& Tsai (2003): "Human beings are by their very nature gregarious creatures, for whom relationships are defining elements of their identities and creativeness. The study of such relationships is therefore the study of human nature itself."

This greater attention to relationships has required that the tools used to analyse the network differ profoundly from the statistical methods used to date in scientific research applied to tourism. These have analysed each component of the destination individually, without considering the relational dimension, i.e., the degree of interaction between the single elements with the entire system.

The Social Network Analysis (SNA) applied to the analysis of tourist destinations allows illustrating and representing the set of relationships between enterprises in a simplified manner through relational maps (Robins et al, 2011). The SNA provides managers the opportunity to understand the logic of operation of the network so as to learn about the features and critical aspects to achieve better destination governance (Baggio, 2011; Baggio \& Del Chiappa, 2014; Baggio, 2013; Baggio et al. 2013).
In both the static and dynamic analysis of tourist destinations, this approach is absolutely necessary, because it adds a dimension hitherto neglected which can impact, more than any other, the success of a tourist destination determining its growth or decline. Knowing the network of a destination means understanding its structure as Wasserman and Faust (1994) argue: "social network analysis focuses its attention on how these interactions constitute a framework or structure that can be studied and analysed in its own right." The multi-disciplinary origin of SNA has led to the creation of a wide range of quantitative measurements that allow identifying the main characteristics of the network (Scott, 2012). Some of the indexes that we use in this article are:

$\checkmark$ Density. It is one of the main statistical descriptors and it is used to indicate the level of cohesion among the enterprises. It summarizes the distance between the situation of maximum integration among the network's enterprises and the level actually measured. (Di Maggio \& Powell, 1983; Scott \&Meyer, 1983). It is calculated as the number of lines of a network compared to the maximum possible number of lines.

$\checkmark$ Geodesic distance. It is the length of the shortest path connecting two players. If the distances are great, the relationship between two firms are more rarefied and pass through other enterprises, which are mediated or are anyhow indirect.

$\checkmark$ Average distance. It is the average of the geodesic distances.

$\checkmark$ Diameter. It is the longest distance connecting two points in a network.

$\checkmark$ Centrality. An enterprise is central if it is "at the centre" of a certain number of relations (degree centrality) and this implies that the links are of considerable importance to the network. In other cases, an enterprise plays a mediating role between different enterprises becoming central to the network (betweenness centrality). In this case the enterprise takes on a certain importance in the coordination functions.

\section{Tourist destination: the network between enterprises}

In addition to the structural elements (Baggio \& Cooper, 2010), the presence or absence of 
specific assets, the territorial dimension (Costa, 2000), and the role and composition of stakeholders and shareholders (Candela \& Figini, 2012), the literature on tourist destinations also addresses some of the conditions that allow destinations to grow and develop (Scott I, 2012). These are dealt with in a broader and more thorough manner in the tourism cluster model whose main condition is the presence of a multitude of enterprises interacting with one another. In this paradigm, a tourist destination becomes a place of relationships and interactions between firms, or the place where there is business originating from economic, social and production relations (Dredge, 2014). This space of social and economic interaction is composed of individuals who, like the nodes of a relational grid, though productive, are responsible for establishing or maintaining the set of formal, informal, economic and social ties underlying the operation of the entire tourist destination.

However, the presence of these relationships is not enough to explain the systemic operation of the destination. The reasons are to be sought in relational dynamics as well as in the role played by each subject within the grid (Lienert et al., 2013). Therefore, the possible interactions and collaboration between firms do not often depend on individual determination or technical capacity, but is due to the role that these have within the destination. In particular, in some cases, it depends on the extent to which they are recognized as system leaders or have a dense consolidated network of trust relationships, such as to be identified as leaders of the system and central figures in its operation vis-à-vis other enterprises.

At many destinations, though, there are conditions of aggregation between enterprises, characterized by the presence of either leading enterprises that are recognized as being leaders of the system or satellite enterprises that keep out of the cooperation and collaboration system marginalizing their role (Kimbu \& Ngoasong, 2013).

Therefore, collaborating with a system of companies or being a satellite enterprise is a binary choice of the individual entrepreneur who decides to join a formalized system of established rules or to follow his own independent strategies.

The presence of different roles played by the enterprises and the various possible aggregations among them in a cluster or subcluster draws attention to how the network of enterprises is structured (Novelli et al., 2006; Mistilis et al. 2014).

This paper aims at highlighting that the presence of formal, informal, intense, complex and concentrated relationships between firms does not explain per se how the tourist destination system works. In this network the presence of system leaders, satellite enterprises and groups of undertakings are to be identified to gain greater insight into the role of each.

The different relational configurations and different weights of the individual firms compared with the others in the system (better defined as nodes) can offer an overall view of the destination, revealing its strengths (relevant companies or leaders), and its weaknesses (satellite enterprises, uncooperative firms, marginal or marginalized businesses).

Small tourist destinations are mainly characterized by a widespread presence of micro-businesses which need to cooperate with one another. Cooperation is often felt to be a necessity and is encouraged by tourism policies aimed at growth and development (Carrà et al., 2016). However, it encounters resistance or driving forces in the relational configuration and in the structure of relationships between companies with different roles.

\section{The Social Network Analysis for ego network findings}

An ego-network is a network consisting of a single actor (ego) together with the actors they are connected to (alters) and all the links among those alters" (Everett \& Borgatti 2005). These networks are also known as "neighbourhood networks of ego" or "first order neighbourhoods of ego". Bott (1957) was one of the first to focus attention on research into ego-networks. He understood that within small networks it is possible to "exert consistent 
informal pressure on one another to conform to the norms, keep in touch with one another, and, if need be, to help one another." The ego tends to create links with those entities that are consistent with their schematic expectations (Kilduff \& Tsai, 2003) in order to better manage the structure of the links that it forms around itself (Simpson et al., 2011). This ability to choose the entities that will become part of one's own network is facilitated in a global structure of links in which there is a low density (Bott 1957). In the latter situation, there is a lack of a set of shared institutional rules and this leads entities to be more likely to establish relationships with those that are recognized to be leaders. Within this tighter network, the entities involved are urged to share norms and values that characterize the ego and in this sense, one can understand why leadership creates the social capital (Balkundi, Kilduff \& Harrison, 2011). Therefore, the ego is led to invest in relationships with the others, adding and/or subtracting players from its network in order to improve its performance and that of the network (Afuah, 2013; Maggioni \& Uberti, 2011) and be present in the other networks (which it is not part of) through the alters. These two motivations have different impacts on the whole network. For the enterprises, the first characteristic entails the opportunity to have a common growth basis (as is that of a small network) (Burt, 2009) and allows them to create new ties (Scott, \& Davis, 2015) with entities with which they did not have relations before but which know themselves through the egonetwork. Ongoing interaction in time and the exchange of information can yield innovations in services and products (Tortoriello, Reagans \& McEvily, 2012). The second characteristic, on the other hand, improves management of the whole network because it allows the players (or nodes) to be able to reach one another through the least number of ties (Sytch, Tatarynowicz, \& Gulati, 2012).

This leads to a micro-analysis of the egonetworks using some indices such as density, connectivity (Burt, 2009) or the location of the alters. The reason why the focus is not limited only to density lies in the fact that, as Mitchell argued (1969): "our interest is primarily in reachability since norm enforcement may occur through transmission of opinions and attitudes along the links of a network. A dense network may imply that this enforcement is more likely to take place than a sparse one but this cannot be taken for granted. The pattern of the network must also be taken into consideration."

\section{The network survey}

The territory where the analysis of the relational network was conducted is San Vito Lo Capo, one of the best examples in Sicily of a successful tourist destination. The choice is due to the rapid development of the tourism in the destination (Haugland et al, 2011): in ten years, the "official" overnight stays (table 1) in the locality increased by $45 \%$, from 352,980 (2003) to 508,659 (2012). This data does not include tourists who sleep in private homes, because they are not monitored by statistics. The increase of tourism demand has created a new supply, consisting mainly of B\&B's (over $70 \%$ ) and other small-to-medium-sized nonhotel accommodations.

Table 1. Number of overnights from 2003 to 2012

\begin{tabular}{cc}
\hline Year & Number of overnights \\
\hline 2003 & 352,980 \\
2004 & 375,757 \\
2005 & 390,426 \\
2006 & 442,295 \\
2007 & 452,973 \\
2008 & 429,244 \\
2009 & 437,378 \\
2010 & 497,886 \\
2011 & 514,812 \\
2012 & 508,659 \\
\hline
\end{tabular}

Source: based on Province of Trapani data

This development is now defined as a spontaneously growing tourist destination, thanks to the collaboration and cooperation between operators who are mainly local people. The presence of this "host community" is to be sought for in the network of relationships of mutual trust and guidance toward a balanced and widespread development open to all (Panyik et al, 2011).

In order to gain greater insight into the bonds and reasons behind this development, and following on the survey carried out in a previous study (Ruggieri \& lannolino, 2014), the authors' attention was focused on the relational ties between the enterprises 
(observation unit - R) consisting in mutual commercial relations or in bonds of kinship. The tourism companies of San Vito Lo Capo (analysis unit - $\mathrm{N}$ ) reported in the table belong to several economic sectors (ATECO 2007).

The survey was carried out through a questionnaire applying the Social Network Analysis technique to a total of 80 enterprises that took part in the survey. The answers of the questionnaires that were filled out directly by managers or entrepreneurs of tourism enterprises were loaded and entered into an adjacency matrix, i.e., a data matrix, in accordance with the Social Network Analysis methodology. The answers were processed with the Ucinet 6 software package (Borgatti, Everett, and Freeman, 2002), obtaining two $80 \times 80$ square matrices: one to process the commercial relations data (commercial matrix) and another to process the data relating to relations of kinship (relative matrix). The calculation of the specific SNA indices shows the presence of a complex grid of relationships, as illustrated and analysed in the paragraphs below.

\section{Ego Network Analysis: graphs}

The continued growth of tourism demand and the subsequent organization of the supply over the last ten years have made it possible to set up a network of relations between enterprises in the town of San Vito Lo Capo. The cluster of enterprises that have driven growth, as demonstrated (Ruggieri \& Iannolino, 2012), are characterized by a high density of commercial relationships supported by bonds of trust among relatives. The presence of three family clusters was then demonstrated. They collaborate regularly with one another and play a central role in terms of trade relations with enterprises at the destination. The enterprises identified and grouped together according to relative relations are the following:

Table 2. San Vito Lo Capo Survey - 2010

\begin{tabular}{llcc}
\hline Code Description & $\begin{array}{c}\text { Number of } \\
\text { tourism } \\
\text { enterprises }\end{array}$ & $\begin{array}{c}\text { Composition of } \\
\text { the analysis unit } \\
\text { in percent }\end{array}$ \\
\hline HAC Hotels and similar establishments & 32 & $34 \%$ \\
AAC Room rentals for short stays, vacation homes and & 27 & $29 \%$ \\
RES Catering with the serving of food and beverages & 18 & $19 \%$ \\
OTH Other booking services and related activities & 6 & $6 \%$ \\
CAC Camping grounds and equipped areas for campers and & 4 & $4 \%$ \\
TRA Trailers & 2 & $2 \%$ \\
REC Car and light motor vehicle rental & 2 & $2 \%$ \\
ADV Travel agency and tour operator activities & 2 & $2 \%$ \\
RAC Holiday villages & 1 & $1 \%$ \\
\hline & TOTAL & $\mathbf{9 4}$ & $\mathbf{1 0 0 \%}$
\end{tabular}

Source: Based on data of the network of Chambers of Commerce

Table 3. The three subgroups of enterprises

\begin{tabular}{cc}
\hline Cluster & Enterprises \\
\hline 1 & hac1;hac23;hac28;cac3;hac17;hac30;res15 \\
2 & hac4;res1;aac14;hac2; hac7;aac6 \\
3 & aac5;aac7;hac31;res2;aac1
\end{tabular}

Legend. $\mathrm{HAC}=$ Hotels and similar establishments; $\mathrm{AAC}=$ Room rentals for short stays, vacation homes and apartments, $\mathrm{B} \& \mathrm{~B}$, apartments, housing connected to farms; RES= Restaurants with service; CAC= Camping grounds and areas for campers and trailers

Source: Data processed by the authors 


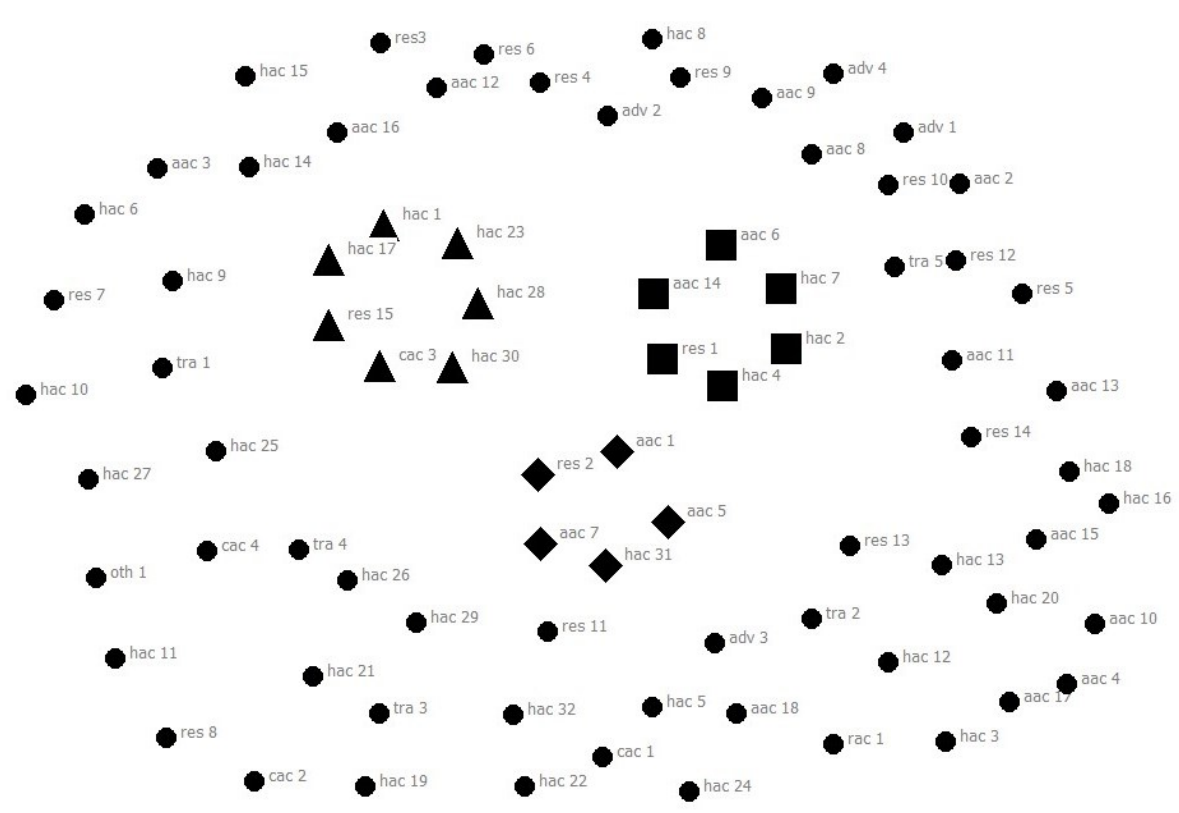

Figure 2. The three subgroups of family ties and commercial relationships - San Vito Lo Capo

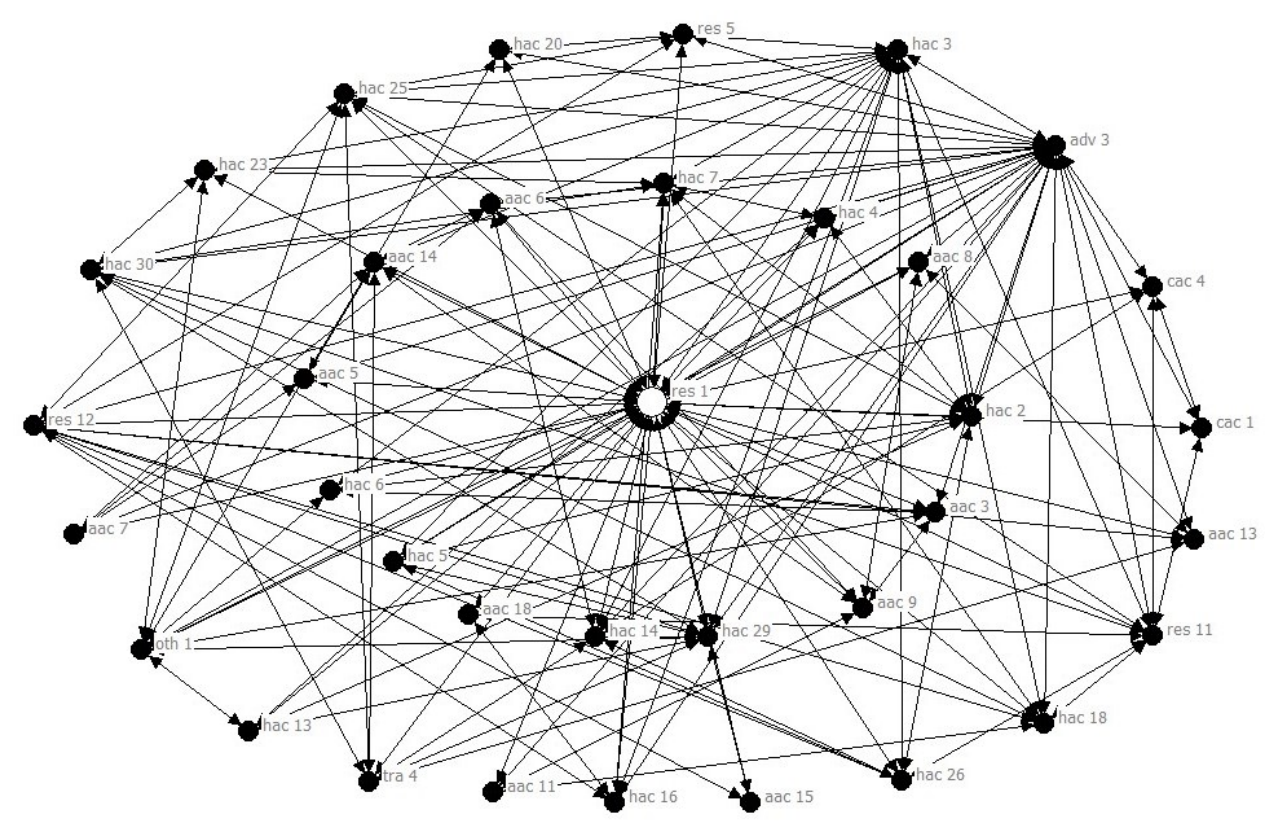

Figure 3. Ego network of the enterprise with the most single relationships res_1

The next step now is to explore the role played by each enterprise within the three families. It is based on the likely hypothesis that within these clusters, each enterprise may have more or less commercial relationships with other firms in the system. In this way, we will obtain the enterprises with most relationships in the system and other enterprises with a small number of relationships. Therefore, the ego network analysis makes it possible to know 
both the quantity of relationships of each enterprise, called Ego, with all the other firms at the destination, as well as to illustrate and analyse the individual network (Ego-network).

The graphical representation is an example of ego network in which firm res_1, which belongs to cluster 2 , has the largest number of business relationships with firms at the tourist destination. It is a catering business that has a commercial network with 35 other firms.

A second example is represented by firm hac_31, a member of cluster 3 , which has a limited number of commercial relationships with the firms in the tourist destination. It has only 6

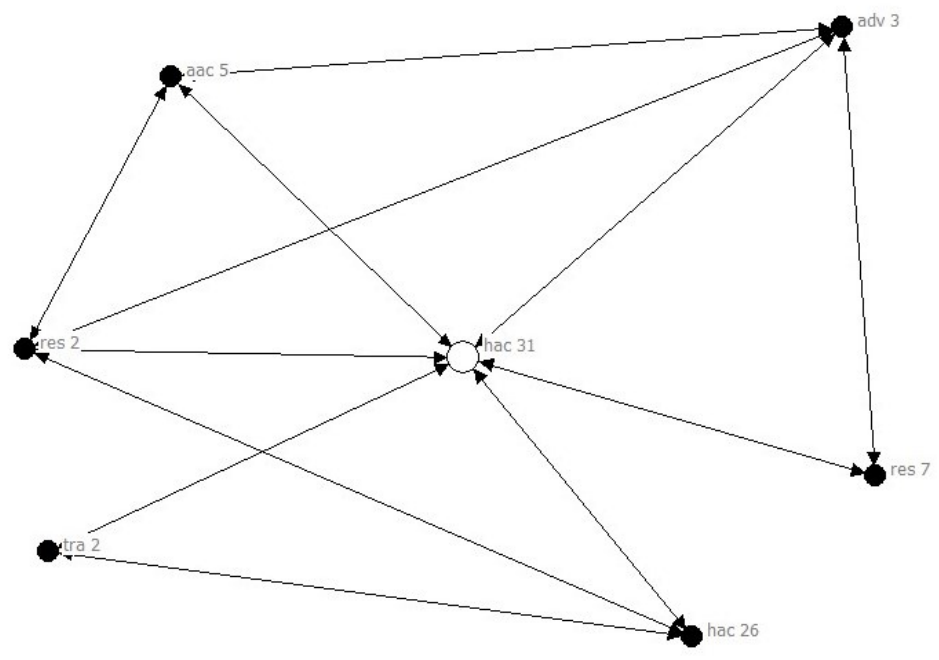

Figure 4. Ego network of the enterprise with least single relationships hac_31



Figure 5. The three subgroups of family related to the entire destination 
commercial relationships and it belongs to the hospitality system. By extending the graphical analysis to each enterprise belonging to a relative cluster, the result is a map of the influences exerted by families on the entire system. Illustrating the aggregate of ego networks shows the map of influences exerted by groups of enterprises belonging to the three families. This network is slightly smaller than the destination of its aggregate, since it connects 73 enterprises out of a total of 80 . The firms not included in this map of links, called satellite firms, are those that exclude themselves from the system of direct relations with the enterprises of the three relative clusters.

A first graphical approach has shown that the leadership role played by families as the core of business aggregates explains the operation of the entire system of commercial relations at the destination. Families are able to assure credibility, reassurance, relationships and trust. In order to better explain the leadership role (Lemmetyinen \& Go, 2009) played by the three families (when these cooperate with one another), the size, composition and relationality of the individual ego-networks needs to be analysed.

\section{Ego Network Analysis: characteristics}

For each family, it has been calculated the influence degree of the network calculated as the percentage of enterprises that the family can directly reach.

Table 4. Influence of the families on the tourist destination

\begin{tabular}{cc}
\hline Family & Degree of influence \\
\hline Cluster 1 & $62.5 \%$ \\
Cluster 2 & $60 \%$ \\
Cluster 3 & $46.25 \%$ \\
\hline
\end{tabular}

Source: Data processed by the authors

The data shows that the first two families are able to influence more than $60 \%$ of the enterprises in the network of the destination, while the third family shows a lower degree of conditioning the behaviour of the enterprises that are part of the tourist destination (see

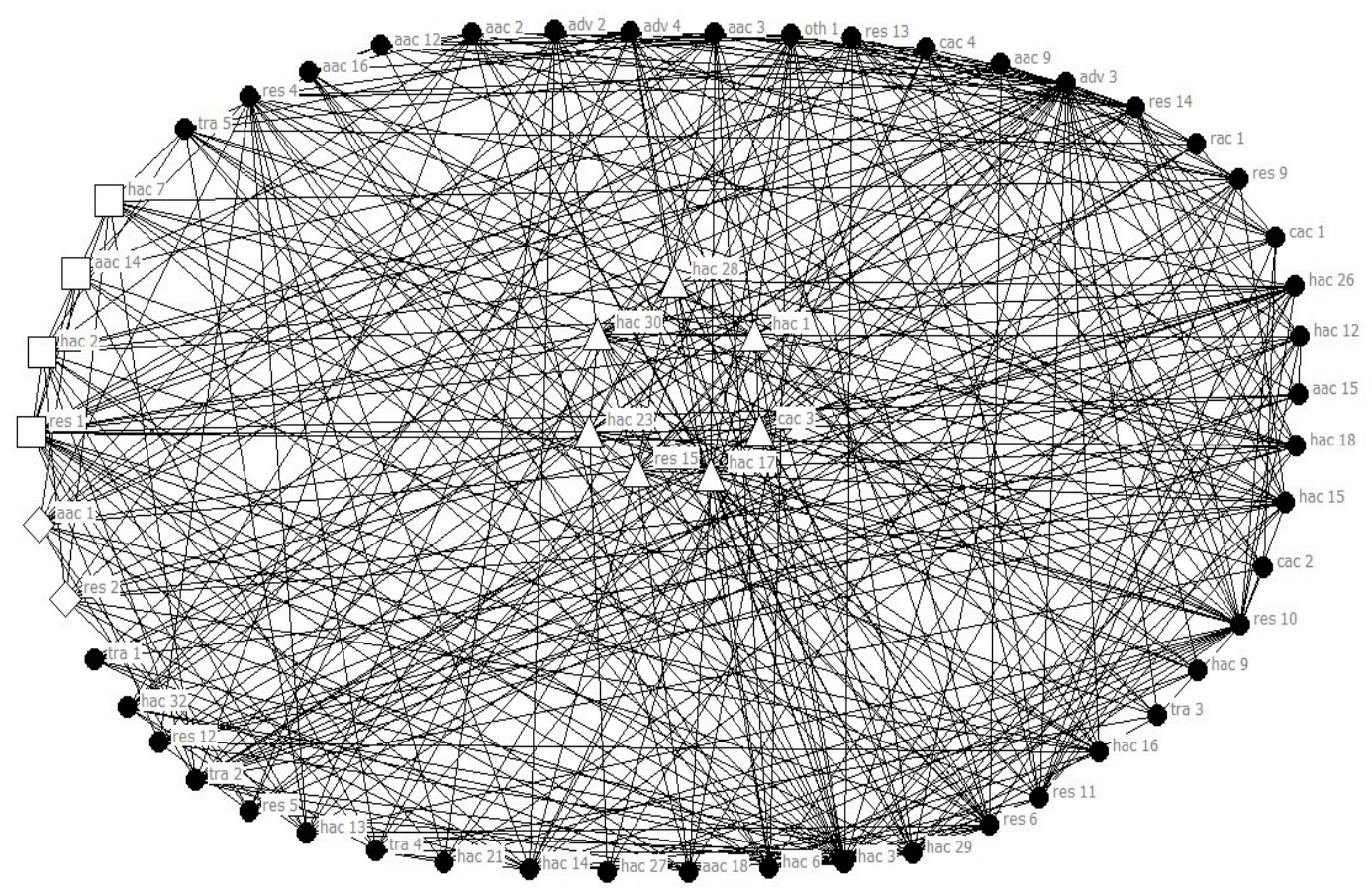

Legend. Triangles: enterprises belonging to family 1; aquares: enterprises belonging to family 2 connected to family 1 ; diamonds: enterprises belonging to family 3 connected to family 1 ; circles: enterprises of the tourist destination that are connected to family 1 and do not belong to any of the three families.

Figure 6. "Family 1" network 


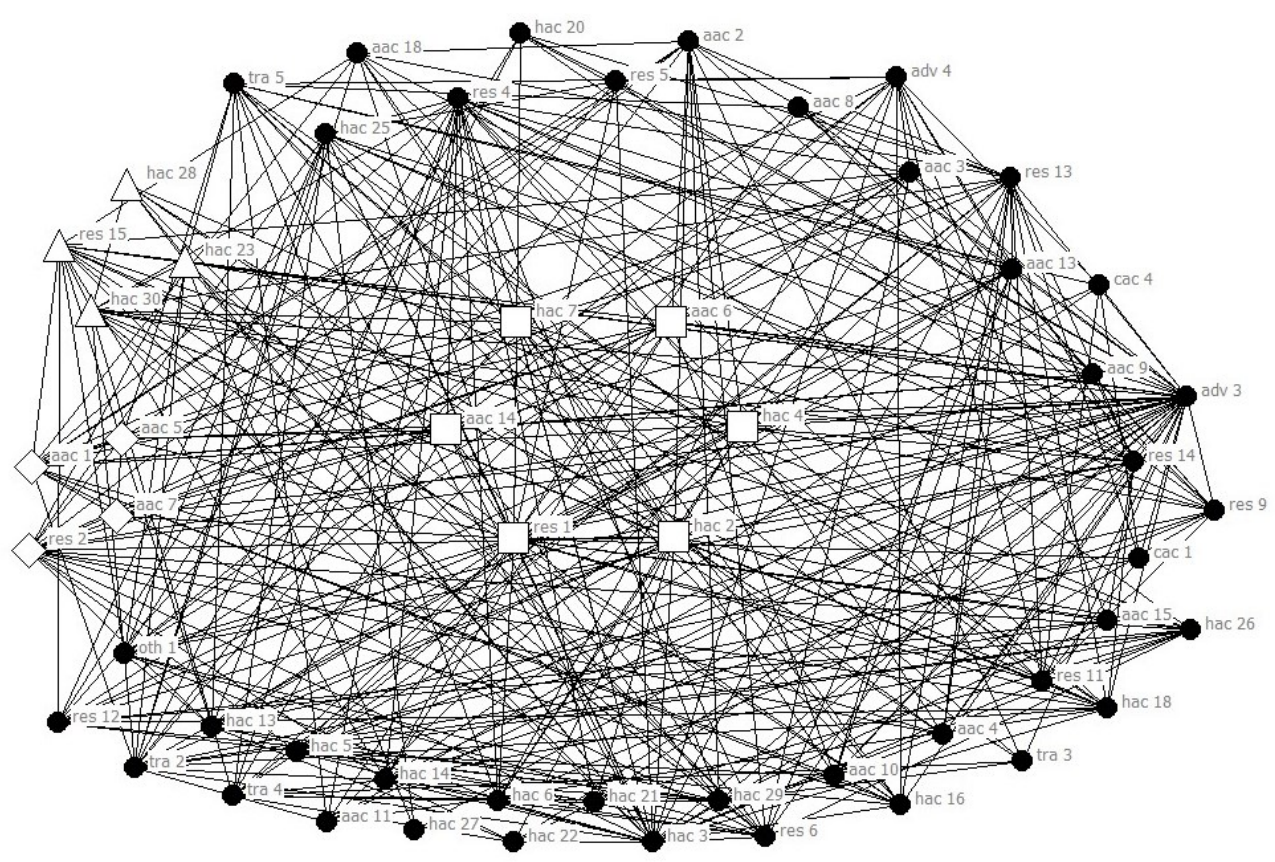

Legend. Squares: enterprises belonging to family 2; triangles: enterprises belonging to family 1 connected to family 2 ; diamonds: enterprises belonging to family 3 connected to family 2 ; circles: enterprises of the tourist destination connected to family 2 and not belonging to any of the three families.

Figure 7. "Family 2" network



Legend. Diamonds: enterprises belonging to family 3; squares: enterprises belonging to family 2 connected to family 3 ; triangles: enterprises belonging to family 1 connected to family 3 ; circles: enterprises of the tourist destination connected to family 3 and not belonging to any of the three families.

Figure 8. "Family 3" network 
Table 4, Figures 6, 7 and 8), but as you will see later, its contribution is crucial in the management of the entire network as a support to the actions of the other two families.

An analysis of the three clusters density reveals something interesting (see Table 5).

Table 5. Analysis of the network created by families

\begin{tabular}{ccc}
\hline Family network & Density & Standard deviation \\
\hline Cluster 1 & 0.5050 & 0.9342 \\
Cluster 2 & 0.5131 & 0.9616 \\
Cluster 3 & 0.5784 & 0.9901 \\
\hline
\end{tabular}

Source: Data processed by the authors

According to Scott (2012), network density created by families increases because they are smaller networks built (created) from the central core. Furthermore, we notice that the standard deviation is a significant indicator of high variability of the links inside. So, there will be enterprises with many ties and others with few ties within the sub-network family. Analysing connections of individual enterprises, which are part of the network, we realize that those which have more connections are the same that belong to the three families. Therefore, further analysis will be useful by examining the ego-network that the individual family members can create (see tables 6,7 and 8).

A first feature that distinguishes the egonetwork is its size (column size of Tables 6,7 and 8 ), which depends on the number of direct relations obtained by each enterprise. It should be noted that in each family every parent has a network of different sizes. The various members of the families were classified based on this parameter.

Table 6. Characteristics of the ego-network belonging to family 1

\begin{tabular}{lllllll} 
& Size & Density & AvgDis & Diameter & EgoBet & nEgoBe \\
\hline hac 30 & 25.00 & 39.67 & 1.61 & 3.00 & 48.27 & 16.09 \\
res 15 & 22.00 & 31.17 & 1.77 & 3.00 & 68.25 & 29.55 \\
hac 23 & 21.00 & 37.14 & 1.68 & 3.00 & 48.25 & 22.98 \\
cac 3 & 19.00 & 39.18 & 1.66 & 3.00 & 39.35 & 23.01 \\
hac 17 & 18.00 & 38.56 & 1.68 & 3.00 & 37.47 & 24.49 \\
hac 1 & 16.00 & 40.00 & 1.63 & 3.00 & 27.01 & 22.51 \\
hac 28 & 10.00 & 44.44 & 1.78 & 3.00 & 16.53 & 36.74
\end{tabular}

Legend: Size: Size of ego network; Density: Ties divided by Pairs; AvgDist: Average geodesic distance; Diameter: Longest distance in egonet; Ego Betweenness: Betweenness of ego in own network; Normalized Ego Betweenness: Betweenness of ego in own network

Source: Data processed by the authors

Table 7. Characteristics of the ego-network belonging to family 2

\begin{tabular}{lllllll} 
& Size & Density & AvgDis & Diameter & EgoBet & nEgoBe \\
\hline res 1 & 35.00 & 18.66 & 1.99 & 4.00 & 257.14 & 43.22 \\
hac 2 & 20.00 & 32.63 & 1.74 & 3.00 & 54.33 & 28.59 \\
hac 7 & 13.00 & 46.15 & 1.56 & 3.00 & 14.62 & 18.74 \\
aac 6 & 12.00 & 42.42 & 1.62 & 3.00 & 16.43 & 24.90 \\
aac 14 & 12.00 & 40.91 & 1.64 & 3.00 & 16.63 & 25.20 \\
hac 4 & 10.00 & 46.67 & 1.58 & 3.00 & 9.82 & 21.81
\end{tabular}

Legend: Size: Size of ego network; Density: Ties divided by Pairs; AvgDist: Average geodesic distance; Diameter: Longest distance in egonet; Ego Betweenness: Betweenness of ego in own network; Normalized Ego Betweenness: Betweenness of ego in own network

Source: Data processed by the authors 
Table 8. Characteristics of the ego-network belonging to family 3

\begin{tabular}{lllllll} 
& Size & Density & AvgDis & Diameter & EgoBet & nEgoBe \\
\hline res 2 & 22.00 & 23.38 & 1.87 & 3.00 & 86.54 & 37.46 \\
aac 1 & 21.00 & 30.95 & 1.78 & 3.00 & 66.65 & 31.74 \\
aac 5 & 10.00 & 31.11 & - & - & 21.67 & 48.15 \\
aac 7 & 6.00 & 80.00 & 1.20 & 2.00 & 0.60 & 4.00 \\
hac 31 & 6.00 & 40.00 & 1.93 & 4.00 & 6.50 & 43.33
\end{tabular}

Legend: Size: Size of ego network; Density: Ties divided by Pairs; AvgDist: Average geodesic distance; Diameter: Longest distance in egonet; Ego Betweenness: Betweenness of ego in own network; Normalized Ego Betweenness: Betweenness of ego in own network

Source: Data processed by the authors

The analysis of the components involved within each ego-network has shown that:

$\checkmark$ in families 2 and 3 the first and second egonetworks involve respectively $91.67 \%$ and $97.3 \%$ of all firms in their own family clusters. However, the first and second ego-network of family 1 can comprise only $74 \%$ of all firms involving their own families (the percentage rises to $90 \%$ if the third ego-network is included);

$\checkmark$ the first components of families 1 and 2 involve all the remaining members of their families in their networkwhile in family 3 only members with a network of median size can involve all family members in its network (Tables 9, 10 and 11);

$\checkmark$ in the ego-network of family 1 there is a low participation of family 3 (only the nodes res 15 and hac 23 involve a member of family 3 ); also family 3 has the same behaviour (with only node aac 1 involving a member of family 1 ). In this situation, family 2 mediates the relationship between the two families in their ego-network involving both members of family 1 and the members of family 3 (Tables 9,10 and 11 ).

Table 9. Members of the three families within the ego-network belonging to family 1

\begin{tabular}{cccccccccccccccccccc} 
& hac & ha & hac & hac & hac & hac & hac & aac & aac & aac & aac & cac & res & res & res & hac & aac & hac \\
& 30 & 28 & 23 & 4 & 1 & 7 & 2 & 14 & 1 & 5 & 6 & 3 & 1 & 15 & 2 & 17 & 7 & 31 \\
\hline hac 30 & 0 & 1 & 1 & 0 & 1 & 1 & 0 & 0 & 0 & 0 & 0 & 1 & 1 & 1 & 0 & 1 & 0 & 0 \\
res 15 & 1 & 0 & 1 & 0 & 1 & 0 & 0 & 1 & 1 & 0 & 0 & 0 & 0 & 0 & 0 & 0 & 0 & 0 \\
hac 23 & 1 & 1 & 0 & 0 & 1 & 1 & 0 & 0 & 0 & 0 & 0 & 1 & 1 & 1 & 1 & 1 & 0 & 0 \\
cac 3 & 1 & 1 & 1 & 0 & 1 & 0 & 0 & 0 & 0 & 0 & 0 & 0 & 0 & 0 & 0 & 0 & 0 & 0 \\
hac 17 & 1 & 0 & 1 & 0 & 0 & 0 & 0 & 0 & 0 & 0 & 0 & 0 & 0 & 0 & 0 & 0 & 0 & 0 \\
hac 1 & 1 & 1 & 1 & 0 & 0 & 0 & 0 & 0 & 0 & 0 & 0 & 1 & 0 & 1 & 0 & 0 & 0 & 0 \\
hac 28 & 1 & 0 & 1 & 0 & 1 & 0 & 1 & 0 & 0 & 0 & 0 & 1 & 0 & 0 & 0 & 0 & 0 & 0 \\
\hline
\end{tabular}

Source: Data processed by the authors

Table 10. Members of the three families within the ego-network belonging to family 2

\begin{tabular}{ccccccccccccccccccc} 
& \cline { 2 - 4 } & hac & hac & hac & hac & hac & hac & aac & aac & aac & aac & cac & res & res & res & hac & aac & hac \\
& 30 & 28 & 23 & 4 & 1 & 7 & 2 & 14 & 1 & 5 & 6 & 3 & 1 & 15 & 2 & 17 & 7 & 31 \\
\hline res 1 & 1 & 0 & 1 & 1 & 0 & 1 & 1 & 1 & 0 & 1 & 1 & 0 & 0 & 0 & 0 & 0 & 1 & 0 \\
hac 2 & 0 & 1 & 0 & 1 & 0 & 1 & 0 & 0 & 0 & 0 & 0 & 0 & 1 & 0 & 1 & 0 & 0 & 0 \\
hac 7 & 1 & 0 & 1 & 1 & 0 & 0 & 1 & 0 & 0 & 0 & 0 & 0 & 1 & 0 & 1 & 0 & 0 & 0 \\
aac 6 & 0 & 0 & 0 & 0 & 0 & 0 & 0 & 1 & 1 & 0 & 0 & 0 & 1 & 0 & 1 & 0 & 1 & 0 \\
aac 14 & 0 & 0 & 0 & 0 & 0 & 0 & 0 & 0 & 1 & 1 & 1 & 0 & 1 & 1 & 0 & 0 & 1 & 0 \\
hac 4 & 0 & 0 & 0 & 0 & 0 & 1 & 1 & 0 & 0 & 0 & 0 & 0 & 1 & 0 & 1 & 0 & 0 & 0 \\
\hline
\end{tabular}

Source: Data processed by the authors 
Tourist destination network analysis: The ego network role.

Table 11. Members of the three families within the ego-network belonging to family 3

\begin{tabular}{cccccccccccccccccccccc} 
& hac & hac & hac & hac & hac & hac & hac & aac & aac & aac & aac & cac & res & res & res & hac & aac & hac \\
& 30 & 28 & 23 & 4 & 1 & 7 & 2 & 14 & 1 & 5 & 6 & 3 & 1 & 15 & 2 & 17 & 7 & 31 \\
\hline res 2 & 0 & 0 & 1 & 1 & 0 & 1 & 1 & 0 & 0 & 1 & 1 & 0 & 0 & 0 & 0 & 0 & 0 & 1 \\
aac 1 & 0 & 0 & 0 & 0 & 0 & 0 & 0 & 1 & 0 & 1 & 1 & 0 & 0 & 1 & 0 & 0 & 1 & 0 \\
aac 5 & 0 & 0 & 0 & 0 & 0 & 0 & 0 & 1 & 1 & 0 & 0 & 0 & 1 & 0 & 1 & 0 & 1 & 1 \\
aac 7 & 0 & 0 & 0 & 0 & 0 & 0 & 0 & 1 & 1 & 1 & 1 & 0 & 1 & 0 & 0 & 0 & 0 & 0 \\
hac 31 & 0 & 0 & 0 & 0 & 0 & 0 & 0 & 0 & 0 & 1 & 0 & 0 & 0 & 0 & 1 & 0 & 0 & 0 \\
\hline
\end{tabular}

Source: Data processed by the authors

Each member of the family lives in a world (represented by the ego-network) where its members are not well connected to each other (as represented by the low index density value (Tables 6, 7 and 8)). This data is even more interesting if compared with the index of Average geodesic distance (AvgDist) (Tables 6, 7 and 8). The latter is essentially similar for each ego-network and this means that, inside, each relationship between two nodes is mediated by a third part. This led us to determine what was the main node providing this service and, through the betweenness and Normalized Ego Betweenness indices (see Tables 6, 7 and 8), it was found that each family member (ego) provides for this mediation (role) within its network.

The ego betweenness indices measure the percentage of all geodesic paths from neighbour to neighbour passing through ego and Normalized Betweenness compares the actual betweenness of ego to the maximum possible betweenness in the neighbourhood of the size and connectivity of egos. The maximum value for betweenness would be achieved where the ego is the center of a "star" network; that is, no neighbours communicate directly with one another, and all directed communications between pairs of neighbours go through the ego. The enterprises that are involved in the ego networks present at the destination acknowledge the leadership of the ego enterprise (Zehrer et al., 2014). Moreover, the index of ego betweenness helps us to highlight that subjects, for each family, are more active in mediating relationships within their network. As noted earlier, also in this case the heads of the first two ego-networks of families 2 and 3 are the most efficient in this context while, as regards family 1 , the central role of the first three members of the family is confirmed.
The above considerations lead us to believe that for every family there are some subjects that have a place of honour and importance within their families, in connection to their business and turnover developed. In this context, we realize that the other members of the family support the activities of most prominent members. This high cooperation can be explained only if there are trust relationships among the enterprises (Huang \& Wilkinson, 2014). This trust built within the families is also extended to relations between the families in order to coordinate their actions to directly influence the $91.3 \%$ of enterprises (equal to 73 units) at the tourist destination of San Vito Lo Capo and to consolidate their positions and their prestige.

\section{Final consideration for tourist destination building}

The results in this paper point to a series of implications for practice and research. This paper demonstrates the contribution of network analysis to understanding the structure and cohesiveness of destinations. NA is particularly useful as it adopts destination approach as a whole and does not focus on any single element. From a methodological point of view, the availability of analytical and visualization software provides a major advantage for analysts because it allows them to highlight weaknesses in destination structures that can be addressed by policy and management approaches. Furthermore, the application of NA to the case study in this paper help us to understand stakeholders of the destination. The studies dissected the structure of the tourism industry in San Vito Lo Capo. The choice of this town is due to the rapid development of tourism from 2003 to 2012 through cooperation between operators, mainly local people. At this destination, the stakeholders are three families. 
The importance of families is demonstrated through both regular collaboration they have with the other families and the central role they play in terms of trade relations with all enterprises at the destination. Indeed, the presence of ties of kinship is the basis of the commercial relations of the three high density clusters.

The visualization of the relationships and structural positions of stakeholders makes the approach especially useful, as the structures can be easily interpreted by managers and shared with the destination stakeholders themselves. While these results are valuable, much work needs to be done to develop a research agenda for NA in tourism. An important evolution in this direction is represented by the ego-network technique that allows us to analyse all links, which a single family member (ego) has with the other destination members (alters) and all the links among those alters. It should be noted that, according to Nee (1998), the origin of effective cooperation is "produced spontaneously in the course of social interactions in networks of personal relations," a less complex structure of personal interactions which generally occurs in smaller groups.

By analysing the links of an individual family, a single member is not able to influence and manage the entire destination. However, when the prominent members of a family cooperate with one another they are able to manage the destination. Indeed, in families 2 and family 3 the first and the second ego-network are able to reach and influence respectively $91.67 \%$ and $97.3 \%$ of the enterprises involved in their family cluster. Communication intensity reinforced through multiple rounds of cooperation as well as effectiveness of establishing contact (in line with transaction cost economics) foster collaboration. Hence, in order to increase cooperation or launch collective action, planners must pay attention to previously established bonds of trust and understanding among actors, recognizable through intense communication; a fundamental condition which has been described in an exploratory study, so far (Saxena, 2016).

In effect, this cooperation repeated over time, consolidates trust in actors and, in the case of San Vito Lo Capo, identifies for every family certain subjects that have a place of honor and importance within their families, in connection to their business and the turnover developed. In this context, the other members of the family support the activities of most prominent members. This high degree of cooperation can be explained only if there are trust relationships among the enterprises (Huang \& Wilkinson, 2014). This trust created within families is also extended to relations between families in order to coordinate their actions to directly influence $91.3 \%$ of enterprises (equal to 73 units) at the tourist destination of San Vito Lo Capo to consolidate their positions and their prestige.

The paper has its limitations. First, the results are valid for one destination and could reflect the idiosyncratic behaviour of individuals in a local/regional culture, which is different from those at other destinations. Second, the research in this paper reflects only a point in time. An important area of future research will be to simulate past and future destination networks, based upon their current characteristics. Thrift (1996) observes that networks are dynamic. They feature relationships among stakeholders that are constantly shifting as they draw together and define the various elements of the network, and as they interact with the external environment (Wilkinson, 2010). Third, no longitudinal data are available in this study but further research in this field could observe particular dimensions like trust and understanding as well as communication, thus contributing to a description of the mechanisms that foster or hinder cooperative behaviour.

\section{References}

Afuah, A. (2013). Are network effects really all about size? The role of structure and conduct. Strategic Management Journal 34(3), 257-273.

Baggio, R., \& Cooper, C. (2010). Knowledge transfer in a tourism destination: the effects of a network structure. The Service Industries Journal, 30(10), 1757-1771.

Baggio, R., Scott, N., \& Cooper, C. (2010). Network science: A review focused on tourism. Annals of Tourism Research, 37(3), 802-827. 
Baggio, R., Scott, N., \& Cooper, C. (2013). Using network analysis to improve tourist destination management. In C. Costa, E. Panyik, \& D. Buhalis (Eds.), Trends in European tourism planning and organisation (pp. 278-288). Bristol: Channel View Publications

Baggio, R. (2011). Collaboration and cooperation in a tourism destination: a network science approach. Current Issues in Tourism, 14(2), 183-189.

Baggio, R. (2013). Studying complex tourism systems: a novel approach based on networks derived from a time series. arXiv preprint arXiv:1302.5909.

Baggio, R., \& Del Chiappa, G. (2014). Real and virtual relationships in tourism digital ecosystems. Information Technology \& Tourism, 14(1), 3-19.

Balkundi, P., Kilduff, M., \& Harrison, D. A. (2011). Centrality and charisma: comparing how leader networks and attributions affect team performance. Journal of Applied Psychology, 96: 1209-1222.

Beritelli, P. (2011). Cooperation among prominent actors in a tourist destination. Annals of Tourism Research, 38(2), 607-629.

Borgatti, S.P., M.G. Everett, L.C. Freeman (2002) Ucinet for Windows: Software for Social Network Analysis. Harvard, MA: Analytic Technologie.

Bott, E. (1957) Family \& Social Network. London: Tavistock.

Burt, R. S. (2009). Structural holes: The social structure of competition. Harvard University Press.

Candela, G., \& Figini, P. (2012). The economics of tourism destinations. Berlin, Heidelberg: Springer.

Carrà, G., Mariani, M., Radić, I., \& Peri, I. (2016). Participatory Strategy Analysis: The Case of Wine Tourism Business. Agriculture and Agricultural Science Procedia, 8, 706712.

Czernek, K. (2013). Determinants of cooperation in a tourist region. Annals of Tourism Research, 40, 83-104.

DiMaggio, P., \& Powell, W. W. (1983). The iron cage revisited: Collective rationality and institutional isomorphism in organizational fields. American Sociological Review, 48(2), 147-160.
Dredge, D. (2014). Tourism-planning network knowledge dynamics. In M. McLeod \& R. Vaughan (Eds.), Knowledge networks and tourism (pp. 9-27). Abingdon: Routledge

Everett, M., \& Borgatti, S. P. (2005). Ego network betweenness. Social Networks, 27(1), 31-38.

Fyall, A., Garrod, B., \& Wang, Y. (2012). Destination collaboration: A critical review of theoretical approaches to a multidimensional phenomenon. Journal of Destination Marketing \& Management, 1(1), 10-26.

Graci, S. (2013). Collaboration and partnership development for sustainable tourism Tourism Geographies, 15(1), 25-42.

Haugland, S. A., Ness, H., Grønseth, B. O., \& Aarstad, J. (2011). Development of tourism destinations: An integrated multilevel perspective. Annals of tourism research, 38(1), 268-290.

Huang, Y., \& Wilkinson, I. F. (2014). A case study of the development of trust in a business relation: Implications for a dynamic theory of trust. Journal of Business Market Management, 7(1), 254-279.

Kilduff, M., \& Tsai, W. (2003). Social networks and organizations. Sage.

Kilduff, M., \& Brass, D. J. (2010). Organizational social network research: Core ideas and key debates. Academy of Management Annals, 4(1), 317-357.

Kimbu, A. N., \& Ngoasong, M. Z. (2013). Centralised decentralisation of tourism development: a network perspective. Annals of Tourism Research, 40, 235-259.

Latour, B. (2013). Reassembling the Social. An Introduction to Actor-Network-Theory. Journal of Economic Sociology, 14(2), 73-87.

Lemmetyinen, A., \& Go, F. M. (2009). The key capabilities required for managing tourism business networks. Tourism Management, 30(1), 31-40.

Lienert, J., Schnetzer, F., \& Ingold, K. (2013). Stakeholder analysis combined with social network analysis provides fine-grained insights into water infrastructure planning processes. Journal of Environmental Management, 125, 134-148.

Maggioni, M. A., \& Uberti, T. E. (2011). Networks and geography in the economics of knowledge flows. Quality \& Quantity, 45(5), 1031-1051. 
Merinero-Rodríguez, R., \& Pulido-Fernández, J. I. (2016a). Analysing relationships in tourism: A review. Tourism Management, 54, 122-135.

Merinero-Rodríguez, R., \& Pulido-Fernández, J. I. (2016b). Network science: A review focused on tourism. Annals of Tourism Research, 37(3), 802-827.

Mistilis, N., Buhalis, D., \& Gretzel, U. (2014). Future eDestination marketing: perspective of an Australian tourism stakeholder network. Journal of Travel Research, 53(6), 778-790.

Mitchell, J. C. (Ed.). (1969). Social networks in urban situations: analyses of personal relationships in Central African towns. Manchester University Press.

Nee, V. (1998). Norms and networks in economic and organizational performance. American Economic Review, 88(2), 85-89.

Novelli, M., Schmitz, B., \& Spencer, T. (2006). Networks, clusters and innovation in tourism: A UK experience. Tourism Management, 27(6), 1141-1152.

Panyik, E., Costa, C., \& Rátz, T. (2011). Implementing integrated rural tourism: An event-based approach. Tourism Management, 32(6), 1352-1363.Perry, M. (2012). Small firms and network economies. London: Routledge. Robins, G., Bates, L., \& Pattison, P. (2011). Network governance and environmental management: conflict and cooperation. Public Administration, 89(4), 1293-1313.

Ruggieri, G., \& lannolino, S. (2012). Tourism destination and the role of trust. Advances in Tourism Studies, McGraw-Hill, Milano.

Ruggieri G. \& lannolino S. (2014), Network analysis of a tourist destination. Malaga: TuridesSaxena, G. (2016). Marketing Rural Tourism: Experience and Enterprise. Cheltenham: Edward Elgar Publishing.
Scott, J. (2012). Social network analysis: A Handbook. London: Sage.

Scott, W. R., \& Davis, G. F. (2015). Organizations and organizing: Rational, natural and open systems perspectives. Routledge.

Scott, W. R. and Meyer, J., (1983). From technology to environment. In J. W. Meyer and W. R. Scott

(Eds.), Organizational Environments: Ritual and Rationality (pp. 13-17). Beverly Hills, CA: Sage.

Simpson, B., Markovsky, B., \& Steketee, M. (2011). Power and the perception of social networks. Social Networks, 33(2), 166-171.

Sytch, M., Tatarynowicz, A., \& Gulati, R. (2012). Toward a theory of extended contact: The incentives and opportunities for bridging across network communities. Organization Science, 23(6), 16581681.

Thrift, N. (1996). Spatial Formations. London: Sage.

Tortoriello, M., Reagans, R., \& McEvily, B. (2012). Bridging the knowledge gap: The influence of strong ties, network cohesion, and network range on the transfer of knowledge between organizational units. Organization Science, 23(4), 10241039.

Wasserman, S., \& Faust, K. (1994). Social network analysis: Methods and applications (Vol. 8). Cambridge: Cambridge University Press.

Wilkinson, I. (2010). Business relating business: managing organisational relations and networks. London: Edward Elgar Publishing.

Zehrer, A., Raich, F., Siller, H., \& Tschiderer, F. (2014). Leadership networks in destinations. Tourism Review, 69(1), 5973. 